Article

\title{
Porosity Characterization of Cold Sprayed Stainless Steel Coating Using Three-Dimensional X-ray Microtomography
}

\author{
Yingying Wang ${ }^{1}$, Jérôme Adrien ${ }^{2}$ and Bernard Normand ${ }^{2, *(D)}$ \\ 1 College of Chemistry and Chemical Engineering, Southwest Petroleum University, Chengdu 610500, China; \\ yingyingwanglyon@126.com \\ 2 MATEIS CNRS UMR 5510, INSA de Lyon, Université de Lyon, Villeurbanne 69621, France; \\ jerome.adrien@insa-lyon.fr \\ * Correspondence: bernard.normand@insa-lyon.fr; Tel.: +33-04-7243-6287
}

Received: 24 July 2018; Accepted: 15 September 2018; Published: 17 September 2018 updates

\begin{abstract}
Cold gas-dynamic spray (cold spray) is an evolving coating deposition and restoration technology in which particles are deposited above the sonic speed. This paper presents the non-destructive three-dimensional characterization of cold sprayed stainless steel coating. The visualization of coating morphology and volumetric porosity and the analyses of porosity size and spatial distributions confirmed that dense stainless steel coating with non-connected, micron-sized gradient porosity can be successfully produced by cold spray. The suitability of X-ray tomography for characterizing cold sprayed coatings was also assessed.
\end{abstract}

Keywords: X-ray tomography; cold spray; porosity; stainless steel; three-dimensional imaging

\section{Introduction}

In recent years, there has been a significant advancement in the applications of cold gas-dynamic spray (also named cold spray) for producing coatings and restoration by high velocity $\left(300-1200 \mathrm{~m} \cdot \mathrm{s}^{-1}\right.$ ) impact of solid metallic powder particles $[1,2]$. The cold spray was originally developed in the mid-1980s at the Institute of Theoretical and Applied Mechanics of the Siberian Division of the Russian Academy of Science in Novosibirsk by Anatolii Papyrin [3]. In this process, powder particles are accelerated by the supersonic gas jet at a temperature that is always lower than the melting point of the deposited material, forming coatings from particles in the solid state. The adhesion of particles in this process is due to their kinetic energy upon impact, and the bonding of particles is attributed to the extremely high strain-rate (up to $10^{9} \mathrm{~s}^{-1}$ ) plastic deformation and adiabatic shear instabilities that occur at the interface [4-6]. Because of the low temperature involved, the deleterious defects of oxidation, phase transformation, decomposition, grain growth and other problems inherent to conventional thermal spray can be minimized or eliminated. Moreover, significant refinement in crystallite size can be obtained after the cold spray deposition [7].

Applications of cold spray technology are improving slowly due to its disadvantages, such as coatings of the certain composition is brittle [8] and the triangular-like profile of single track [9]. Additionally, the incompletely bonded interfaces between the deposited particles may result in porosity and micro-cracks. It is likely that the most concerning property of the cold sprayed coatings is their porosity as it is directly related to the coating quality and performance. In some cold spray operations, porosity is essential. For example, the hydroxyapatite coatings used for prosthetic implants depend on the open-pore structure for attachment to natural bone tissue [10,11]. On the other hand, certain properties could be inferior due to the presence of porosity more than a specific amount. Since 
corrosion protection is partly based on the shielding of the substrate from an aggressive corrosive environment, if the porosity allows a direct path to the substrate, corrosion damage of structure is predictable $[12,13]$. Lower corrosion rate could be achieved due to a denser microstructure with lower porosity $[8,14]$. Mechanical properties can also be affected by porosity. Han et al. measured a SS304 coating in three-point bending and found the elastic modulus is only approximately $117 \mathrm{GPa}$, which is much lower than a nominal value $(200 \mathrm{GPa})$. This reduction in modulus was accredited to the inter-particle porosity [15]. Meng et al. reported very low $(<4 \%)$ values of elongation to fracture for cold sprayed 304SS coatings after annealing. This low ductility was attributed to the persistent presence of porosity even after annealing [16]. The porosity has also been linked to unfavorable fatigue performance [17].

Numerous techniques are available to measure porosity but the most popular one for cold sprayed coatings (as well as for all kinds of thermal sprayed coatings) is optical microscopy or scanning electron microscopy (SEM) coupled with image analysis. Besides porosity, this procedure allows microstructure, thickness, interfaces, cracks and contamination characterizations, and chemical composition analysis when combined with energy eispersive spectrometer (EDS). However, there are some problems with metallographic observations, which we cannot avoid. Firstly, optical (or electron) microscopy is a destructive test. A coupon is produced using the specified spray parameters and then destroyed during the preparation, including sectioning, cleaning, mounting grinding and polishing prior to microscopic inspection [18]. Since then, the porosity of a part of the product, instead of the porosity of the product, is normally determined. The frequency of testing varies according to the need. Not in all cases, a single qualifying sample is sufficient. In addition, for each test specimen, a great quantity of non-overlapping view fields should be analyzed to get an average result (for example, 20 required in ASTM E1920 [19]). Another issue is that the metallographic preparation could induce adverse influence to the specimen by detaching particles or smearing material over voids. Secondly, this is an area of measurement, in which the reliability based on the area of porosity obtained in 2D is essentially equal to the volumetric porosity (3D) [20] as long as the pores are small and uniformly distributed. However, even though satisfying results with high precision and low bias are obtained from statistical analysis, the total porosity of the deposit does not have significant meaning for many applications. More crucial information about the morphology and distribution of porosity in three-dimension (open, closed, tortuosity and connected pores to name a few) is missed. Taking the hydroxyapatite biocomposites coating again as an example, a gradient porosity level is useful as bone tissues as it can grow into open pores, creating a mechanical hinge and eliminating the need for cement [10]. Furthermore, controlling or adjusting porosity is desired in quite a few applications. As a first step, visualization and characterization of porosity must be actualized.

The X-ray tomography, one of the useful non-destructive tools, is a capable candidate to investigate the internal properties [21-23]. The main objective of this study is to determine the opportunity of using X-ray tomography as a technique for an accurate characterization of volumetric porosity in cold sprayed coatings. Three-dimensional visualization of porosity within cold sprayed stainless steel coating using 3D X-ray tomography is presented. Quantitative information on microstructural features with respect to the size distribution and spatial distribution of porosity is obtained using open software Image with the $3 \mathrm{D}$ image processing package Fiji.

\section{Materials and Methods}

Commercial atomized stainless steel 316L powder particles with nominal size ranges of 10-45 $\mu \mathrm{m}$ were used as the feedstock, in which the irregular morphology is shown in Figure 1. A commercial cold spray system (PCS-1000, Plasma Giken Co., Ltd., Saitama, Japan) was employed. Working gas was $\mathrm{N}_{2}$ with a pressure of $3 \mathrm{MPa}$. The main gas temperature was $950{ }^{\circ} \mathrm{C}$. The spray distance was $30 \mathrm{~mm}$. Powder feed rate was $150 \mathrm{~g} \cdot \mathrm{min}^{-1}$. The substrate was an aluminum 6061 plate in order to increase absorption contrast between the coating and the substrate. A field emission scanning electron microscope (FE-SEM, Supra ${ }^{\circledR} 55$ VP, Carl Zeiss NTS GmbH, Oberkochen, Germany) was 
used to observe the cross-sectional microstructure of the coating. The microhardness was tested by a Vickers hardness indenter (Buehler MicroMet 5104, Buehler LTD, Lake Bluff, Illinois, USA) under a load of $100 \mathrm{~g}$ and a dwell time of $15 \mathrm{~s}$. Ten values at random locations on the central region of polished cross-section was averaged.

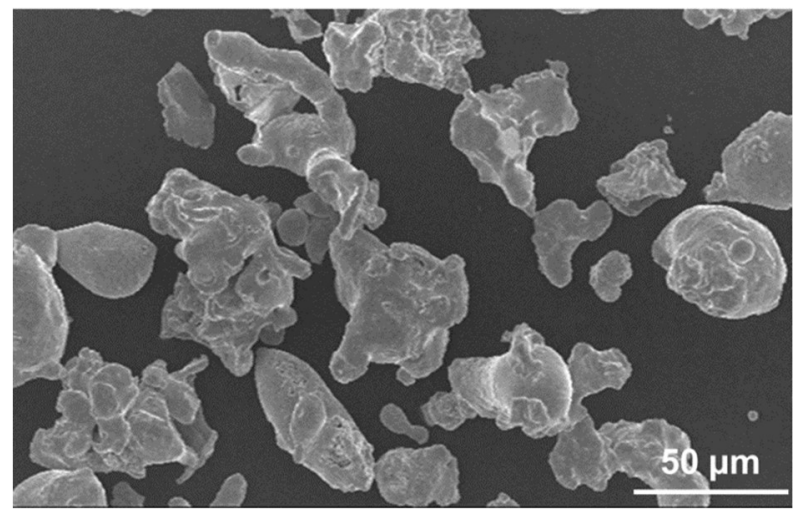

Figure 1. SEM image of irregularly shaped stainless steel 316L feedstock powder used.

X-ray tomography consisted of acquiring a series of X-ray radiographs of a sample that rotated step by step around an axis perpendicular to the incident beam. The spatial density distribution was then reconstructed by using a standard filtered back-projection algorithm [24]. Inner microstructure observation of the coating was performed using a standard laboratory tomography designed by the company RX Solutions (Raleigh, NC, USA). A very high resolution (compared to currently available cone beam laboratory systems) was achieved in this lab kit by using a new Hamamatsu X-ray Source (Hamamatsu Photonics, Shizuoka, Japan). It achieved a spot size of $0.7 \mu \mathrm{m}$ when using a $\mathrm{W}$ filament and this size could even be reduced further by using $\mathrm{a} \mathrm{LaB}_{6}$ cathode $(0.25 \mu \mathrm{m})$. The X-ray source was operated with the $\mathrm{LaB}_{6}$ cathode at a voltage of $100 \mathrm{kV}$. The detector was a Hamamatsu CMOS Flat Panel with a pixel size of $50 \mu \mathrm{m}$ [25]. The samples were scanned at a voxel size of $1.8 \mu \mathrm{m}$. Each scan consisted of 1200 projections with an averaging of 5 radiographs for each.

\section{Results}

Figure 2 shows the cross-sectional SEM micrographs of the cold sprayed stainless steel 316L coating. It can be found that the deposited particles present plastic deformed morphologies, and porosity is randomly distributed. On the top surface, the deformation is not sufficient to fill in all the gaps between the deposited particles. The porous top layer is formed due to the absence of the tamping effect of next incoming particles. Nonetheless, there are no visible micro-channels through the coating from the top to the interface. The porosity measured on SEM micrographs is about $1.5 \% \pm 0.4 \%$. The measurement of microhardness yields $325 \pm 41 \mathrm{HV} 0.1$, which is comparable with the results by Li et al. who used spherical atomized 316L stainless steel powder and high-pressure compressed air as the accelerating gas [26]. Meanwhile, the microhardness is lower than the results (393 \pm 14 HV0.1) reported by Al-Mangour et al. with $4 \mathrm{MPa}$ gas pressure [27] and the average hardness (400 HV0.1) by Adachi et al. with 3.5 MPa gas pressure [28].

Figure 3 shows 3D reconstructed view of cold sprayed stainless steel coating and 3D rendering of the porosity's structure. In Figure $3 a$, the grey surface in the $x y$ plane is the top surface of the coating, and the bottom is the interface, which bonds with the substrate. Because of the small size and the small quantity of porosity, the porosity network present is a zoomed view focused in a smaller zone (Figure $3 b$ ). The coating surface is connecting to the air (the continuous yellow object on the top). Pores embedded in the coating (yellow objects) show irregular morphology and a larger quantity of pores located on the upper part than on the bottom part. At the coating-substrate interface, porosity is also 
higher than the main part of the coating. From the top surface to interface, no channels constructed from connected pores are detected.

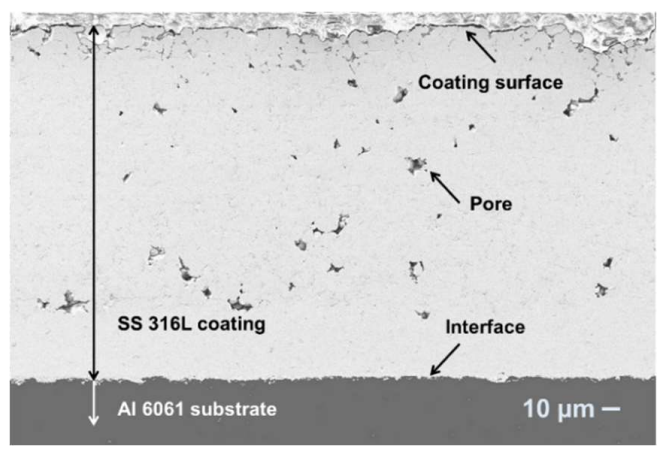

Figure 2. Cross-sectional SEM micrographs of cold sprayed stainless steel 316L coating.
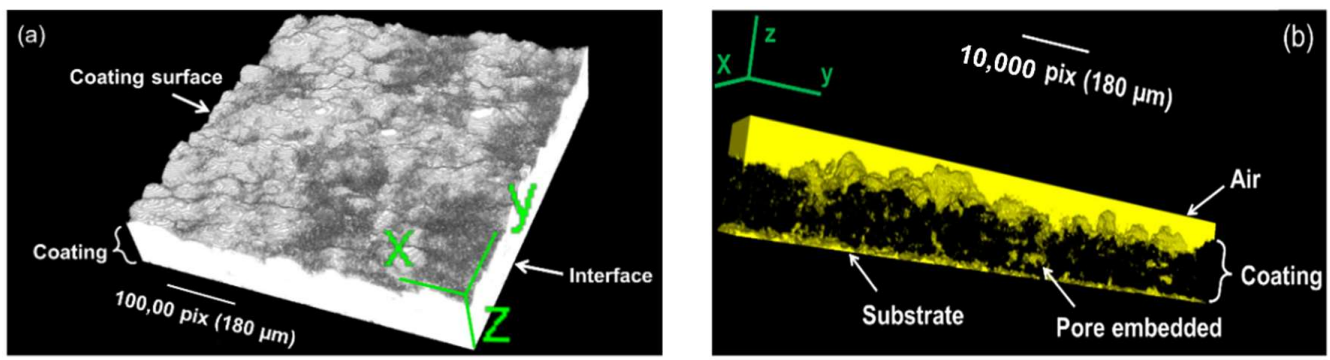

Figure 3. 3D reconstructed views of (a) cold sprayed stainless steel coating and (b) porosity network.

Figure 4 shows the tomogram image corresponding to 2D reconstructed tomographic slices of the $y$-axis stacking (cross-section from the view vertical to $y$-axis). In this absorption contrast image, the brightest intensity is found in stainless steel coating, dark grey corresponds to aluminum 6061 substrate, and black to air and pores in the coating. Coating shows the same dense cross-sectional microstructure as examined with SEM in Figure 2.

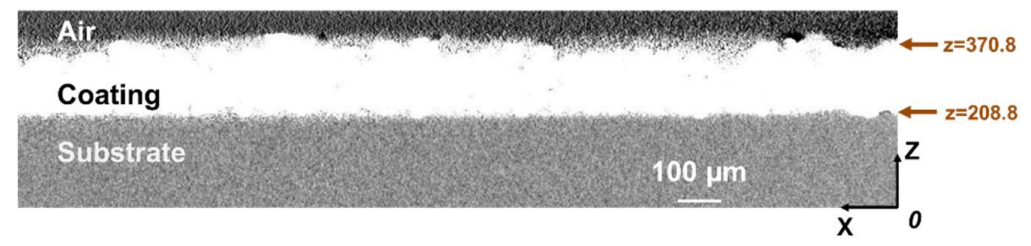

Figure 4. Reconstructed cross-section of cold sprayed SS 316L coating by tomogram image corresponding to $2 \mathrm{D}$ slices of the $y$-axis stacking.

From these qualitative visualizations, 3D quantitative analyses have been performed. Typical profiles of coating density and porosity values along the three main perpendicular directions $(x, y$ and $z$ ) are plotted in Figure 5. Coating density and porosity distribution in $x$ direction and $y$ direction is quite homogeneous. However, in $z$ direction (in which the thickness is building), a gradient in the porosity is observed. At the position $z=208.8 \mu \mathrm{m}$, there is a peak of porosity which corresponds to the coating-substrate interface. As illustrated by H. Assadi et al. [29] and Sunil Pathak et al. [30], bonding in cold spray is considered to identify with interfacial deformation, which prompts the breakup of surface oxide layers and enables the contact of metallic surfaces at the atomic level. They proposed that the oxide layer should be considered as a geometrical constraint to metallurgical bonding (Figure 6). Hence, the likely reason for the porosity peak at the interface could be due to the native oxide layer. Before deposition, the Al6061 substrate had not undergone any surface pretreatment (neither sand blasting nor polishing). During spraying, the particles roughly impact the substrate and disrupt 
the oxide layer. The fractured aluminum oxide layer results in noncontinuous bonding. Moreover, the computational analysis demonstrates that in the initial stage of particle-substrate interaction phenomena, a thin film of particle material is deposited on the substrate. This stage depends very much on the degree of substrate surface preparation, as well as on the properties of the substrate material [31]. The native oxide layer on the aluminum substrate influence the strain condition at the particle-substrate interface and the injection of interfacial jets from the substrate surface. This results in inadequate interfacial bonding.
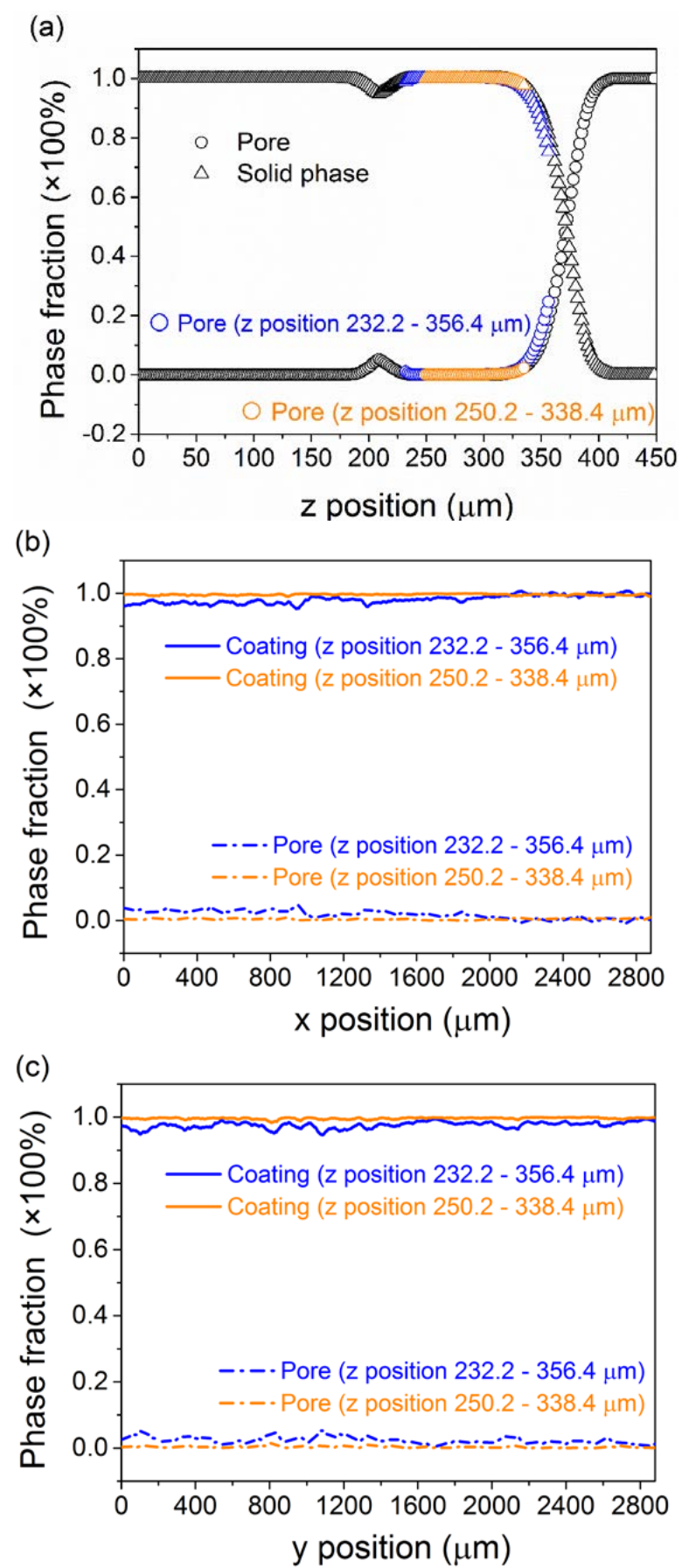

Figure 5. Porosity profiles of the cold sprayed stainless steel coating along the (a) $z$, (b) $x$ and (c) $y$ directions. Origin of coordinates $(x$ and $z$ ) is marked in Figure 3. 


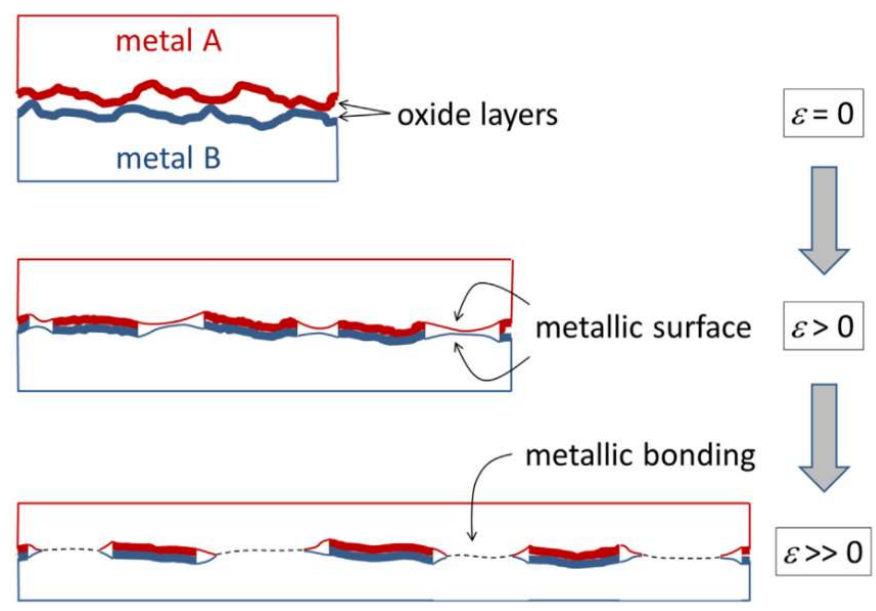

Figure 6. Schematics of interfacial plastic deformation resulting in cold welding. Under high strains, there is contact between fresh metallic surfaces and grain boundaries are formed between the two metals [29].

In Figure 5, the porosity fraction along the certain axis is the porosity measured on the series of planes that are vertical to the assigned axis based on the grey level. The average porosity reaches $1.8 \%$ along $x$ direction and $2.4 \%$ along $y$ direction (on the thickness direction, $z$ is restricted from 208.8 to $370.8 \mu \mathrm{m})$. The inner coating layer ( $z$ ranging from 250.2 to $338.4 \mu \mathrm{m}$ ) is denser, and the average porosity fractions reach $0.4 \%$ along $x$ direction and $0.3 \%$ along $y$ direction.

Another important issue about porosity is the opened or closed nature of pores. The connectivity of each selected phase (solid or gaseous) can be determined by a counting procedure detecting the 3D independent objects [32]. Each object, defined as a cluster of connected voxels, can then be labeled by a different grey level on resulting tomographic slices. For the tested specimen, in total 19,467 non-connected objects are labeled in the coating, and their size distribution is calculated (Figure 7). Totally, $94.56 \%$ of pores have a smaller size than $100 \mu \mathrm{m}^{3}$ including $44.32 \%$ of pores smaller than $10 \mu \mathrm{m}^{3}$. The total voxel volume of pores (129,511 pixels) and total voxel volume of coating $(21,490,676$ pixels) result in a volumetric porosity of $0.6 \%$. This value is lower than the porosity measured by traditional methods $(1.5 \% \pm 0.4 \%$ as mentioned). The difference may result from the different size of specimens and different resolution of techniques. The non-connected porosity of low level and small size promises good corrosion protection for the aluminum substrate [33,34].

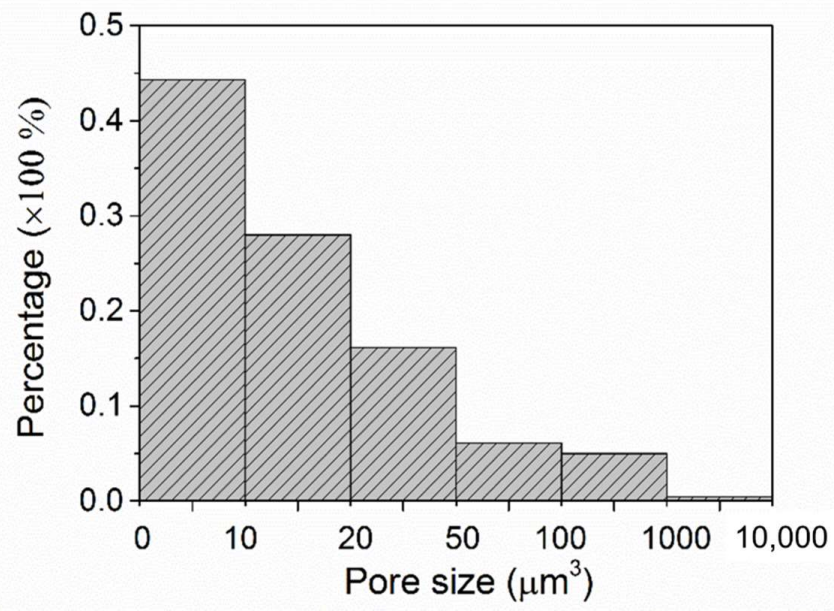

Figure 7. Pores size distribution of cold sprayed stainless steel coating. 


\section{Conclusions}

This study proposed that cold sprayed stainless steel coating can display a micro-sized and non-connected porosity of low level. The fluctuating on porosity profile in $z$ direction could help to identify the interface and measure coating thickness. Conversely, the lack of porosity peak at the interface is helpful to determine the spray parameters required for strong coating-substrate adhesion. Therefore, X-ray tomography technique provides the three-dimensional architecture of cold sprayed coating in a non-contact and non-destructive way, and it proposes a direct visualization of voids in three-dimensional space. Microstructure, thickness, porosity fraction, pore's connectivity and size distribution are interesting parameters that can be measured from tomographic images. More work is in progress to demonstrate this opportunity and more applications on the characterization of composite coatings.

Author Contributions: Y.W. and B.N. conceived and designed the experiments; Y.W. and J.A. performed the experiments; Y.W., J.A. and B.N. analyzed the data; Y.W. and B.N. wrote the paper.

Funding: This research was funded by the National Natural Science Foundation of China (No. 51601158) and the Qihang Science Research Foundation of Southwest Petroleum University (No. 2015QHZ013).

Acknowledgments: The authors thankfully acknowledge Plasma Giken Co., Ltd. for providing free samples supporting the research on cold spraying at INSA de LYON.

Conflicts of Interest: The authors declare no conflict of interest.

\section{References}

1. Cavaliere, P. Cold-Spray Coatings: Recent Trends and Future Perspectives; Springer International Publishing: Cham, Switzerland, 2017; ISBN 9783319671826.

2. Singh, H.; Sidhu, T.S.; Kalsi, S.B.S. Cold spray technology: Future of coating deposition processes. Fract. Strut. Integr. 2012, 6, 69-84. [CrossRef]

3. Papyrin, A.; Kosarev, V.; Klinkov, S.; Alkhimov, A.; Fomin, V.M. Cold Spray Technology, 1st ed.; Papyrin, A., Ed.; Elsevier: Oxford, UK, 2007; ISBN 008046548X.

4. Assadi, H.; Gärtner, F.; Stoltenhoff, T.; Kreye, H. Bonding mechanism in cold gas spraying. Acta Mater. 2003, 51, 4379-4394. [CrossRef]

5. Wu, J.; Fang, H.; Yoon, S.; Kim, H.; Lee, C. The rebound phenomenon in kinetic spraying deposition. Scr. Mater. 2006, 54, 665-669. [CrossRef]

6. Suhonen, T.; Varis, T.; Dosta, S.; Torrell, M.; Guilemany, J.M. Residual stress development in cold sprayed Al, $\mathrm{Cu}$ and Ti coatings. Acta Mater. 2013, 61, 6329-6337. [CrossRef]

7. Brewer, L.N.; Schiel, J.F.; Menon, E.S.K.; Woo, D.J. The connections between powder variability and coating microstructures for cold spray deposition of austenitic stainless steel. Surf. Coat. Technol. 2018, 334, 50-60. [CrossRef]

8. AL-Mangour, B.; Mongrain, R.; Irissou, E.; Yue, S. Improving the strength and corrosion resistance of 316L stainless steel for biomedical applications using cold spray. Surf. Coat. Technol. 2013, 216, 297-307. [CrossRef]

9. Kotoban, D.; Grigoriev, S.; Okunkova, A.; Sova, A. Influence of a shape of single track on deposition efficiency of 316L stainless steel powder in cold spray. Surf. Coat. Technol. 2017, 309, 951-958. [CrossRef]

10. Choudhuri, A.; Mohanty, P.S.; Karthikeyan, J. Bio-ceramic composite coatings by cold spray technology. In Proceedings of the 2009 International Thermal Spray Conference, Las Vegas, NV, USA, 4-7 May 2009; pp. 391-396.

11. Lee, J.H.; Jang, H.L.; Lee, K.M.; Baek, H.-R.; Jin, K.; Hong, K.S.; Noh, J.H.; Lee, H.-K. In vitro and in vivo evaluation of the bioactivity of hydroxyapatite-coated polyetheretherketone biocomposites created by cold spray technology. Acta Biomater. 2013, 9, 6177-6187. [CrossRef] [PubMed]

12. Tao, Y.; Xiong, T.; Sun, C.; Kong, L.; Cui, X.; Li, T.; Song, G.-L. Microstructure and corrosion performance of a cold sprayed aluminium coating on AZ91D magnesium alloy. Corros. Sci. 2010, 52, 3191-3197. [CrossRef]

13. Marrocco, T.; Hussain, T.; McCartney, D.G.; Shipway, P.H. Corrosion performance of laser posttreated cold sprayed titanium coatings. J. Therm. Spray Technol. 2011, 20, 909. [CrossRef] 
14. Hassani-Gangaraj, S.M.; Moridi, A.; Guagliano, M. Critical review of corrosion protection by cold spray coatings. Surf. Eng. 2015, 31, 803-815. [CrossRef]

15. Han, W.; Meng, X.M.; Zhang, J.B.; Zhao, J. Elastic modulus of 304 stainless steel coating by cold gas dynamic spraying. J. Iron Steel Res. Int. 2012, 19, 73-78. [CrossRef]

16. Meng, X.; Zhang, J.; Zhao, J.; Liang, Y.; Zhang, Y. Influence of gas temperature on microstructure and properties of cold spray 304SS coating. J. Mater. Sci. Technol. 2011, 27, 809-815. [CrossRef]

17. Al-Mangour, B.; Dallala, R.; Zhim, F.; Mongrain, R.; Yue, S. Fatigue behavior of annealed cold-sprayed 316L stainless steel coating for biomedical applications. Mater. Lett. 2013, 91, 352-355. [CrossRef]

18. ASTM E2109 Test Methods for Determining Area Percentage Porosity in Thermal Sprayed Coatings; American Society for Testing and Materials: West Conshohocken, PA, USA.

19. ASTM E1920 Standard Guide for Metallographic Preparation of Thermal Sprayed Coatings; American Society for Testing and Materials: West Conshohocken, PA, USA.

20. Friel, J.J. Practical Guide to Image Analysis; ASM International: Almere, The Netherlands, 2000; ISBN 1615032371.

21. Maire, E.; Grenier, J.; Daniel, D.; Baldacci, A.; Klöcker, H.; Bigot, A. Quantitative 3D characterization of intermetallic phases in an Al-Mg industrial alloy by X-ray microtomography. Scr. Mater. 2006, 55, 123-126. [CrossRef]

22. Madison, J.D.; Aagesen, L.K. Quantitative characterization of porosity in laser welds of stainless steel. Scr. Mater. 2012, 67, 783-786. [CrossRef]

23. Maurel, V.; Helfen, L.; N'Guyen, F.; Koster, A.; Di Michiel, M.; Baumbach, T.; Morgeneyer, T.F. Three-dimensional investigation of thermal barrier coatings by synchrotron-radiation computed laminography. Scr. Mater. 2012, 66, 471-474. [CrossRef]

24. Youssef, S.; Maire, E.; Gaertner, R. Finite element modelling of the actual structure of cellular materials determined by X-ray tomography. Acta Mater. 2005, 53, 719-730. [CrossRef]

25. Etiemble, A.; Adrien, J.; Maire, E.; Idrissi, H.; Reyter, D.; Roué, L. 3D morphological analysis of copper foams as current collectors for Li-ion batteries by means of X-ray tomography. Mater. Sci. Eng. B 2014, 187, 1-8. [CrossRef]

26. Li, W.-Y.; Liao, H.; Douchy, G.; Coddet, C. Optimal design of a cold spray nozzle by numerical analysis of particle velocity and experimental validation with 316L stainless steel powder. Mater. Des. 2007, 28, 2129-2137. [CrossRef]

27. Al-Mangour, B.; Vo, P.; Mongrain, R.; Irissou, E.; Yue, S. Effect of heat treatment on the microstructure and mechanical properties of stainless steel 316L coatings produced by cold spray for biomedical applications. J. Therm. Spray Technol. 2014, 23, 641-652. [CrossRef]

28. Adachi, S.; Ueda, N. Effect of cold-spray conditions using a nitrogen propellant gas on AISI 316L stainless. Coatings 2017, 7, 87. [CrossRef]

29. Assadi, H.; Kreye, H.; Gärtner, F.; Klassen, T. Cold spraying-A materials perspective. Acta Mater. 2016, 116, 382-407. [CrossRef]

30. Pathak, S.; Saha, G.C. Development of sustainable cold spray coatings and 3D additive manufacturing components for repair/manufacturing applications: A critical review. Coatings 2017, 7, 122. [CrossRef]

31. Grujicic, M.; Saylor, J.R.; Beasley, D.E.; DeRosset, W.S.; Helfritch, D. Computational analysis of the interfacial bonding between feed-powder particles and the substrate in the cold-gas dynamic-spray process. Appl. Surf. Sci. 2003, 219, 211-227. [CrossRef]

32. Elmoutaouakkil, A.; Salvo, L.; Maire, E.; Peix, G. 2D and 3D characterization of metal foams using X-ray tomography. Adv. Eng. Mater. 2002, 4, 803-807. [CrossRef]

33. Wang, Y.; Normand, B.; Mary, N.; Yu, M.; Liao, H. Effects of ceramic particle size on microstructure and the corrosion behavior of cold sprayed SiC p/Al 5056 composite coatings. Surf. Coat. Technol. 2017, 315, 314-325. [CrossRef]

34. Wang, Y.; Normand, B.; Suo, X.; Planche, M.-P.; Liao, H.; Tang, J. Cold-sprayed AZ91D coating and $\mathrm{SiC} / \mathrm{AZ91D}$ composite coatings. Coatings 2018, 8, 122. [CrossRef]

(C) 2018 by the authors. Licensee MDPI, Basel, Switzerland. This article is an open access article distributed under the terms and conditions of the Creative Commons Attribution (CC BY) license (http:/ / creativecommons.org/licenses/by/4.0/). 